\title{
Hydrometallurgical Processing of Copper-Smelting Dust
}

\author{
Sokhibjon Turdalievich Matkarimov ${ }^{1}$, Dilfuza Odilovna Yavkochiva ${ }^{2}$, \\ Bahriddin Tilovkabulovich Berdiyarov ${ }^{3}$, Fakhriddin Djailolovich Nosirov ${ }^{4}$ \\ ${ }^{1}$ Deputy Dean of Department, Assistant Professor, Ph.D., Department of Metallurgy, \\ TashkentStateTechnicalUniversity, Tashkent, Uzbekistan. sohibtm@gmail.com \\ ${ }^{2}$ Assistant of the department, Termez Branch of TashkentStateTechnicalUniversity, Termez,Uzbekistan. \\ yavkochiva@gmail.com \\ ${ }^{3}$ Head of Department, Ph.D., DepartmentofMetallurgy, TashkentStateTechnicalUniversity, Tashkent, \\ Uzbekistan.mr.berdiyarov@mail.ru \\ ${ }^{4}$ Assistant Professor of the department, Ph.D., Termez Branch of TashkentStateTechnicalUniversity, \\ Termez,Uzbekistan.nosirov-0173@mail.ru
}

\begin{abstract}
The article says the possibility of using copper smelting dust to neutralize sulfuric acid. This allows very expensive copper pellets not to be used for these purposes. The phase, mineralogical and chemical composition of dust studied, and the possibility of their processing by hydrometallurgical methods established. The optimal mode of water and sulphuric acid leaching of copper from the dust of the metallurgical plant was found. It was determined that the processing of oxygen-flare smelting dust in a separate cycle would improve the process of Flash Smelting Furnace (FSF) of sulfide copper concentrates, free the furnace from the ballast revolution of dust and increase the furnace capacity by 15- $20 \%$.
\end{abstract}

Key words: Dust, processing, reducing agent, zincclinker clinker, chemical reactions, depletion, flotation, ideal mixing apparatus, low-waste production.

\section{INTRODUCTION}

In heavy non-ferrous metals metallurgy, the purpose of smelting is to separate waste rock and part of iron in the form of slag from metal or matte by pyrometallurgical means. In this case, the properties of substances in the molten state are used and delaminated by densities with relatively low solubility of the components of the delaminated system - slag and metal, slag and matte in each other. During melting, complex physicochemical transformations of substances occur under the influence of high temperatures and gas medium [1].

In autogenous processes, a lot of execution is devoted to raw materials. The main requirement for raw materials for autogenous processes is the presence of components that, when interacting with the oxygen of the blast, generate heat sufficient to melt the products. Iron-containing sulfide sulfur is subjected to smelting in autogenous mode.

A feature of copper concentrates melting is the presence of base pyrrhotite and a massive particle tone $(80 \%$ of the $45 \mu \mathrm{m}$ fraction. specific float of the charge, in practice is 25-30 t/m2 - day). The discharge rate of the oxygen mixture from the burners reaches $23 \mathrm{~m} / \mathrm{s}$ since the oxidation rate of the particles in the charge-oxygen flare, and the propagation of the ignition fraction is higher than usual. Dust removal from the furnace is $7-9 \%$ [2-3]. With a daily furnace capacity of 2000 tons, about 2 tons of charge passes into dust. This dust creates severe difficulties for electrofilters, the dust collection system as a whole. According to the existing technology, this dust is again loaded into the furnace and thereby increases dust entrainment.

We suggest that the dust of FSF furnaces be processed in a separate cycle, without loading it again into the oven. In our opinion, it is most advisable to dissolve dust in sulfuric acid and obtain copper cuprous from a sulfate solution. Currently, copper domes are made soluble in copper granules. This is a costly process, requires a lot of material costs, and makes the products unattractive.

Using this dust will significantly reduce costs, reduce costs, and make products competitive in the world market. Of course, this will slightly reduce the quality of the cuprous, but it is quite suitable for use in agriculture, where immaculate materials are not required.

The refusal to re-load dust into the furnace allowed to increase the furnace productivity by $7-10 \%$, significantly reduce the load on electrofilters and the dust collection system as a whole.

It is advisable to charge the dust into the spent electrolyte solution and obtain copper cuprous from it.

At the same time, the technical, economic, and technological indicators of the whole process receive copper as a whole significantly increase.

During the processing of electrolyte into copper cuprous, contaminated mother liquors of the third crystallization of cuprous are simultaneously disposed of, as a result of which non-standard products are obtained: electrolyte copper, aqueous copper-nickel salts. Substandard electrolyte copper is sent for remelting in the anode area of the MPP, and spices, as semi-products of production, are sold to interested organizations [4].

In the process of production of copper cuprous, the following are used as initial technological materials: electrolyte of the cathode section, solutions for dehumidification of sludge, washing waters of cuprous production, condensate and copper granules. Copper pellets diverge to neutralize sulfuric acid contained in the electrolyte to be processed.

World practice shows that it is copper granules that are used to neutralize sulfuric acid. These are expensive 
materials that increase the cost of cuprous and reduce its competitiveness in the world market [4].

\section{METODOLOGY}

The complexity of the phase composition of the FSF dust of copper sulfide concentrates and the limited research on their processing led to a cycle of experiments on leaching dust with various reagents: $\mathrm{HNO}_{3}, \mathrm{H}_{2} \mathrm{SO}_{4}$, a mixture of $\mathrm{H}_{2} \mathrm{O}+\mathrm{H}_{2} \mathrm{O}_{2}, \mathrm{CuSO}_{4}+\mathrm{H}_{2} \mathrm{SO}_{4}$, spent copper and sulfidealkali electrolytes. The results of the studies are presented in Table 1.

Table 1: Results of FSF dust leaching with various reagents

\begin{tabular}{|c|c|c|c|c|c|c|c|c|c|c|c|}
\hline \multirow[b]{2}{*}{ Reagent } & \multicolumn{10}{|c|}{ Compounds of dust } & \multirow{2}{*}{$\begin{array}{c}\text { Exit } \\
\text { cake, } \\
\% \\
\text { ofweight }\end{array}$} \\
\hline & As & Sb & $\mathbf{P b}$ & Zn & $\mathbf{C u}$ & $\mathbf{F e}$ & $\mathbf{S}$ & $\begin{array}{l}\mathrm{Bi}, \\
\mathrm{mg} / \mathrm{l}\end{array}$ & Au & $\begin{array}{l}\text { Ag, } \\
\text { mg/l }\end{array}$ & \\
\hline \multicolumn{12}{|c|}{ Composition of solutions after leaching, g/l } \\
\hline $\mathrm{HNO}_{3}$ & 1,25 & 1,15 & 0,545 & 3,74 & 76,7 & 58,4 & 29,8 & - & 0 & 0 & - \\
\hline $\mathrm{H}_{2} \mathrm{SO}_{4}$ & 1,30 & 1,14 & 0,775 & 5,41 & 77,5 & 65,6 & 27,1 & 47,9 & 0 & 2,5 & - \\
\hline $\mathrm{CuSO}_{4}$ & 0,83 & 0,92 & 0,650 & 2,06 & 45,7 & 15,7 & 26,0 & 0 & 0 & 1,53 & - \\
\hline $\mathrm{CuSO}_{4}+\mathrm{H}_{2} \mathrm{SO}_{4}$ & 1,31 & 1,13 & 0,405 & 5,31 & 76,9 & 64,1 & 27,0 & 61,5 & 0 & 1,84 & - \\
\hline $\begin{array}{l}\text { Copper } \\
\text { electrolyte }\end{array}$ & 1,25 & 1,01 & 0,610 & 3,66 & 66,3 & 44,4 & 26,7 & 34,1 & 0 & 1,71 & \\
\hline $\begin{array}{c}\text { Sulphidicandalkaline } \\
\text { electrolyte }\end{array}$ & 1,08 & 0 & 0,048 & 0,48 & 47,4 & 10,5 & 30,7 & 0 & 0 & 0,75 & \\
\hline $\mathrm{H}_{2} \mathrm{O}_{2}$ & 0,39 & 0,2 & 0,174 & 2,33 & 40,9 & 36,3 & 19,5 & - & 0 & 0 & - \\
\hline \multicolumn{12}{|c|}{ Composition of solutions after leaching, g/l } \\
\hline $\mathrm{HNO}_{3}$ & 0,09 & 0,02 & 17,09 & 1,95 & 1,82 & 11,98 & 3,31 & - & 56,0 & 617,0 & 32,6 \\
\hline $\mathrm{H}_{2} \mathrm{SO}_{4}$ & 0,12 & 0,10 & 24,24 & 0,41 & 5,37 & 5,58 & 12,1 & 0,22 & 91,0 & 560,0 & 21,4 \\
\hline $\mathrm{CuSO}_{4}$ & 0,30 & 0,154 & 8,28 & 2,0 & 19,4 & 29,57 & 4,45 & 0,1 & 28,0 & 230,0 & 63,6 \\
\hline $\mathrm{CuSO}_{4}+\mathrm{H}_{2} \mathrm{SO}_{4}$ & 0,10 & 0,12 & 23,82 & 0,57 & 6,19 & 7,81 & 11,6 & 0,18 & 86,0 & 604,0 & 21,6 \\
\hline $\begin{array}{c}\text { Copper } \\
\text { electrolyte }\end{array}$ & 0,12 & 0,176 & 14,5 & 1,9 & 13,5 & 23,15 & 7,19 & 0,13 & 49,0 & 375,0 & 38,2 \\
\hline $\begin{array}{c}\text { Sulphidicandalkaline } \\
\text { electrolyte }\end{array}$ & 0,10 & 0,894 & 7,25 & 1,8 & 11,5 & 20,24 & 12,3 & 0,07 & 18,0 & 170,0 & 112,0 \\
\hline $\mathrm{H}_{2} \mathrm{O}_{2}$ & 0,55 & 0,02 & 12,43 & 1,65 & 16,64 & 13,07 & 4,89 & - & 33,8 & 373,0 & 55,0 \\
\hline \multicolumn{12}{|l|}{\begin{tabular}{|c|} 
The extent of \\
extraction solution, \%
\end{tabular}} \\
\hline $\mathrm{HNO}_{3}$ & 94,1 & 98,2 & 26,4 & 68,3 & 99,6 & 84,1 & 90,5 & 99,0 & 0 & 0 & - \\
\hline $\mathrm{H}_{2} \mathrm{SO}_{4}$ & 95,0 & 93,9 & 36,3 & 95,0 & 96,5 & 92,1 & 80,0 & 5,8 & 0 & 44,2 & - \\
\hline $\mathrm{CuSO}_{4}$ & 60,5 & 77,2 & 15,8 & 36,5 & 56,7 & 22,0 & 76,6 & 0 & 0 & 27,0 & - \\
\hline $\mathrm{CuSO}_{4}+\mathrm{H}_{2} \mathrm{SO}_{4}$ & 95,5 & 94,3 & 18,7 & 94,0 & 95,8 & 90,1 & 73,6 & 36,0 & 0 & 32,5 & - \\
\hline $\begin{array}{l}\text { Copper } \\
\text { electrolyte }\end{array}$ & 90,1 & 84,5 & 1,96 & 64,8 & 82,4 & 62,3 & 78,1 & 20,0 & 0 & 30,3 & \\
\hline $\begin{array}{c}\text { Sulphidicandalkaline } \\
\text { electrolyte }\end{array}$ & 79,0 & 0 & 2,2 & 8,5 & 58,9 & 14,8 & 90,7 & 0 & 0 & 13,3 & \\
\hline $\mathrm{H}_{2} \mathrm{O}_{2}$ & 40,0 & 97,5 & 11,1 & 55,7 & 68,7 & 72,2 & 78,4 & - & 0 & 0 & - \\
\hline
\end{tabular}

The experiments were carried out in a glass reactor ( 11 capacity) with a mechanical stirrer (- $1000 \mathrm{rpm})$ and a reflux condenser, as well as in autoclaves - "bombs" with a capacity of $100 \mathrm{ml}$, rotating on the axis of the air thermostat [5-7].

When studying the effect of $\mathrm{HNO}_{3}$ on dust, a version of autoclave nitric acid leaching was adopted. Leaching conditions were selected, taking into account the phase composition of the dust: concentration $\mathrm{HNO}_{3} 25 \mathrm{wt} \%$, temperature $110{ }^{\circ} \mathrm{C}, \mathrm{L}: \mathrm{S}=3-4$, time $30-50 \mathrm{~min}$. The results are given in Table 1; dust solubility was $67-88 \%$. Precious metals and lead are concentrated as much as possible in cakes, the rest of the metals, including arsenic antimony, almost completely go into solution, except for zinc, the degree of extraction of which does not exceed $68-69 \%$ [8-11].

Sulphuric acid leaching was carried out with acid use by concentration by the 20th mass of $\%$ during two $h$ at a temperature of $96-98{ }^{\circ} \mathrm{C}, \mathrm{L}: \mathrm{S}=1: 3$.

It was noted that elemental sulfur was formed during the leaching process, which was sublimated on the cold part of the reverse cooler. This dust leaching process is of great importance in the production of elemental sulfur.

Salt leaching with a copper sulfate solution is based on the known fact that some non-ferrous metal sulfides can be dissolved in bivalent copper salts. The process is generally described by the formula: 


$$
\mathrm{MeS}+2 \mathrm{Cu}^{2+}-\gg \mathrm{Me}^{2+}+2 \mathrm{Cu}^{+}+\mathrm{S}^{\circ}
$$

The condition for the development of the process is the presence of sulfides in the raw materials. The solubility of dust in copper sulfate is $36-37 \%$, which indicates a small content of sulfide forms of non-ferrous metals, in particular copper. Acidification of sulfate solutions leads to an increase in the completeness of the recovery of As, $\mathrm{Sb}, \mathrm{Zn}, \mathrm{C}$, and Fe, and cakes are enriched with noble metals and elemental sulfur [12].

Leaching with a copper electrolyte containing up to 170 $\mathrm{g} / 1 \mathrm{H}_{2} \mathrm{SO}_{4}$ and $235 \mathrm{~g} / \mathrm{l}$ copper in terms of $\mathrm{CuSO}_{4}-5 \mathrm{H}_{2} \mathrm{O}$, at a temperature of $95-98{ }^{\circ} \mathrm{C}, \mathrm{L}: \mathrm{S}=1: 3$ for 2 hours leads to dust solubility by $61-62 \%$. However, a noticeable transition to a silver solution was noted, which can be attributed to the underperformance of the method. To explain this fact, research will continue.

Leaching by the sulfide-alkaline electrolyte of the composition $78 \mathrm{~g} / \mathrm{l} \mathrm{Na} 2 \mathrm{~S}$ and $8 \mathrm{~g} / \mathrm{l} \mathrm{NaOH}$ under the above conditions leads to sulfidation of dust; yield of cake from leaching is $112 \%$ of the mass of initial dust. There is an increased recovery of arsenic and copper into the solution; other components are practically not affected [13-14]. Leaching with a hydrogen peroxide solution was studied under agitation conditions at a temperature of $95 \pm 2{ }^{\circ} \mathrm{C}$. The pulp was kept in the reactor for twoh atL:S = 1:3-4. Due to the great exothermic nature of the process, strong pulp hissing was noted, which should be borne in mind when loading a reagent, especially concentrated $25-30 \%$. The solubility of dust was $45-46 \%$, which cannot be considered satisfactory. The complexity of the process and the relatively high cost of $\mathrm{H}_{2} \mathrm{O}_{2}$ also make it impossible to recommend this reagent for leaching.

Comparative analysis of the results of leaching dusts with various reagents to extract valuable components into the liquid phase $(\mathrm{Cu}, \mathrm{Zn})$ makes it possible to recommend nitric and sulfuric acid solutions, acidified copper sulfate solutions, copper electrolyte as a leaching agent. If the processing of the dust is tied directly to copper production, the use of sulfuric acid, spent, and partially acidified copper electrolyte is most useful. It is possible to use neutral or aqueous leaching to recover a water-soluble (sulfate) part of the dust, as well as a combination of neutral and acidic leaching.

Thus, according to the results of water leaching of dust: FSF dust captured by electrofilters, it is quite easy to leach water with the extraction of most of the copper into solution; so, under optimal leaching conditions (70-190 ${ }^{\circ} \mathrm{C} ; 1.0$ - $1.5 \mathrm{~h}$; flow rate $\mathrm{O}_{2} 6 \mathrm{l} / \mathrm{min}$; $\left.\mathrm{L}: \mathrm{S}=1: 3-4\right)$ it is possible to take up to $80 \%$ of copper in solution, and for $87-90 \%$ to leave the iron in the cake;

The copper-containing solutions obtained in the process of aqueous leaching are suitable for electrical release of copper by the content of all components (excluding iron), while the solutions must be previously purified by known methods; at a $\mathrm{Cu}$ content of $5.4-7.5 \%$ in solids, it is necessary to either re-leach - with maximum recovery of $\mathrm{Cu}$ into the solution, or search for another mode of dust opening at lower $\mathrm{pH}$, that is, in a more acidic medium, for example in sulfuric acid.

With neutral-oxidative leaching, the selection of the oxidant is carried out in the optimal mode of water leaching. As an oxidizing agent, known reagents are used - 02 (tech.), $\mathrm{KMnO}_{2}, \mathrm{H}_{2} \mathrm{O}_{2}$. Particular attention should be paid to the dosage of the oxidant, the method and time of its supply to the reaction medium, and the temperature regime.

Hydrogen peroxide is the most suitable and effective oxidizing agent under the test conditions. Optimal is the supply of an oxidant solution 40-60 minutes after the start of the process. Oxidation state of $\mathrm{Fe}_{2}+$ in $\mathrm{Fe}_{3}+12-95 \%$.

The use of an oxidizing agent practically does not affect the behavior of noble metals, lead, nickel, cadmium, cobalt, for the remaining main components, the results of water-oxidizing leaching are as follows.

Table 2:Distribution of main dust components

\begin{tabular}{|c|c|c|c|}
\hline Component & Solutiong/l & Cake, \% & Extraction from solution, \\
\%
\end{tabular}

In the process of water-oxidative leaching, coppercontaining solutions are obtained, the composition of which allows them to be used to produce both cathode copper and copper cuprous. However, the issue of maximum copper recovery is not solved;besides, those components that determine the degree of complexity of the use of dust, for example, Mo, are very slightly extracted. Therefore, further research was aimed at determining the conditions under which all valuable dust components are sufficiently recovered.

As is already known, the water leaching performance in terms of maximum copper recovery is unsatisfactory. For this reason, sulfuric acid leaching of dust carried out both in a reactor with mechanical mixing and air aeration, as well as oxygen supply, was investigated. Sulfuric acid was chosen, taking into account the particular requirements of further stages of the scheme, in particular the electrolysis operation, which is most favorable for sulfate solutions of non-ferrous metals. Leaching was studied depending on temperature, time, L:S ratio, and sulfuric acid concentration (0.7-2 $\mathrm{mmol} / \mathrm{l})$. More dilute acid solutions are less effective in dust solubility, and less dilute (more than $2 \mathrm{~mol} / \mathrm{l}$ ) are aggressive and result in a significant increase in stable residue yield due to various 
secondary processes.For example, complex double or necessary sulfate formation reactions.

The distribution of the principal dust components in their leaching products is shown in Table 2. (experiments were carried out in a 11 glass reactor with a mechanical stirrer, electric heating, and reflux), from which it follows that maximum copper recovery $(95 \%)$ is achieved at an acid concentration of $2 \mathrm{~m}$. The extraction of zinc and other dust components other than lead into the iron one solution is also increased. Based on the results of experiments (Table
3. and 4), carried out in a reactor with a volume of 0.5 liters and mechanical mixing, the following optimal mode of leaching of dust from copper-made FSF electrofilters • sulfuric acid solutions is recommended: temperature 95$98^{\circ} \mathrm{C}$, time 1.5-2.0 hours, $\mathrm{L}: \mathrm{S}=3: 4$, sulfuric acid concentration in water $2 \mathrm{M}$. At the same time, the yield of a solid residue containing up to $20 \%$ lead is $25 \%$ of the initial. In the sediment, noble metals are concentrated. The leaching products have the following composition:

\section{RESULTS}

Table 3:Results of sulphuric acid leaching of dust from electrofilters

\begin{tabular}{|c|c|c|c|c|c|c|c|c|c|c|c|}
\hline \multicolumn{4}{|c|}{ Technological factors } & \multirow{2}{*}{\multicolumn{2}{|c|}{\begin{tabular}{|c|} 
Dryresidueyiel \\
d,
\end{tabular}}} & \multicolumn{2}{|c|}{ Filtercharacteristics } & \multicolumn{4}{|c|}{ Contentinsolidresidue, \% } \\
\hline $\mathbf{t},{ }^{\circ} \mathbf{C}$ & $\underset{\%}{\text { Time, }}$ & $\mathbf{L}: \mathbf{S}$ & $\mathrm{H}_{2} \mathrm{SO}_{4}$ & & & pH & $\underset{\mathrm{g} / \mathrm{sm}}{\mathrm{d},}$ & $\mathbf{C u}$ & $\mathbf{F}_{\text {total }}$ & РЬ & As \\
\hline 35 & 1 & 3 & 1,4 & \multicolumn{2}{|c|}{44,8} & 0,24 & 1,270 & 11,8 & 28,62 & 9,0 & 0,35 \\
\hline 98 & 1 & 3 & 1,4 & \multicolumn{2}{|c|}{31,6} & 0,34 & 1,320 & 7.2 & 23,45 & 14,4 & 0,22 \\
\hline 98 & 2 & 3 & 1,4 & \multicolumn{2}{|c|}{30,6} & 0,06 & 1,315 & 6,65 & 22,75 & 14,8 & 0,18 \\
\hline 98 & 2 & 3 & 2,0 & \multicolumn{2}{|c|}{25,0} & $-0,09$ & 1,372 & 5,0 & 16,75 & 19,2 & 0,21 \\
\hline \multicolumn{8}{|c|}{ Extractioninsolution, \% P,\% } & \multirow{2}{*}{\multicolumn{4}{|c|}{ Observations }} \\
\hline $\mathrm{Sb}$ & $\mathrm{Zn}$ & $\mathrm{Cu}$ & $\mathrm{Fe}_{\text {total }}$ & $\mathrm{Pb}$ & \multicolumn{3}{|l|}{ As } & & & & \\
\hline 0,32 & 1,90 & 74,8 & 28,8 & 13,6 & 79,4 & 20,5 & 22,8 & \multicolumn{4}{|c|}{ Good filtration } \\
\hline 0,34 & 1,50 & 88,6 & 58,8 & 9,0 & 90,9 & 40,2 & 56,9 & \multicolumn{4}{|c|}{ Good filtration } \\
\hline & & & & & & & & \multicolumn{4}{|c|}{$\begin{array}{l}\text { White crystalline precipitate } \\
\text { precipitates from the cooling } \\
\text { solution }\end{array}$} \\
\hline 0,20 & 1,40 & 89,9 & 61,4 & 9,3 & 92,7 & 66,0 & 61,0 & \multicolumn{4}{|c|}{ Excellentfiltration } \\
\hline 0,26 & 0,90 & 94,8 & 76,7 & 4,0 & 94,3 & 64,0 & 79,6 & \multicolumn{4}{|c|}{ Excellentfiltration } \\
\hline \multicolumn{4}{|c|}{ Component } & \multicolumn{4}{|c|}{ The solution, g/l } & \multicolumn{4}{|c|}{ Cake, \% } \\
\hline \multicolumn{4}{|c|}{$\mathrm{C} \Gamma$} & \multicolumn{4}{|c|}{$55-60$} & \multicolumn{4}{|c|}{5,0} \\
\hline \multicolumn{4}{|c|}{$\mathrm{Fe}_{\text {total }}$} & \multicolumn{4}{|c|}{30} & \multicolumn{4}{|c|}{16,7} \\
\hline \multicolumn{4}{|c|}{$\mathrm{Zn}$} & \multicolumn{4}{|c|}{$2,0-2,2$} & \multicolumn{4}{|c|}{0,9} \\
\hline \multicolumn{4}{|c|}{$\mathrm{Pb}$} & \multicolumn{4}{|c|}{0,5} & & & & \\
\hline & & & & & & 1,8 & & & & & \\
\hline & & & & & & 0,3 & & & & & \\
\hline
\end{tabular}

The results of the enlarged laboratory experiments in the reactor with a volume of 2 liters and the supply of air or oxygen are presented in Table 3 . As you can see, dosing even a small amount of oxygen allows you to transfer copper to the solution completely.

However, the iron recovery rate is increased to $82.8 \%$. These parameters are achieved in the following mode: temperature $90{ }^{\circ} \mathrm{C}$, time one $\mathrm{h}, \mathrm{L}: \mathrm{S}=3$, sulfuric acid concentration $2 \mathrm{M}$, oxygen flow $0.65-0.70 \mathrm{l} / \mathrm{min}$. The solid residue yield is $25.2 \%$ of the initial dust charge.
Leaching products have the following composition:

Gold is concentrated in the cake up to $56 \mathrm{~g} / \mathrm{t}$, silver - up to $390 \mathrm{~g} / \mathrm{t}, \mathrm{SiO}_{2}$ - up to $22.1 \%$. Solutions after leaching contain, in addition to the above components, up to 370$380 \mathrm{~g} / \mathrm{l}$ sulfate ions; the density of these solutions is 1.410 $\mathrm{g} / \mathrm{cm}^{3}$ and $\mathrm{pH}=-0.65$ (Table 5).

As thermo- and radiographic studies have shown, solid residues from sulfuric acid leaching of dust are noticeably different from cakes of water leaching. 
Table 4:Results of experiments on water leaching of dust from electrofiltersFSF (dust of class 315 - $50 \mathrm{mcm}$ )

\begin{tabular}{|c|c|c|c|c|c|c|c|c|c|c|c|c|c|}
\hline \multicolumn{3}{|c|}{ Technological factors } & \multicolumn{5}{|c|}{\begin{tabular}{|c|c|}
$\begin{array}{c}\text { Dryresidueyi } \\
\text { eld, } \%\end{array}$ & Filtrateperformanc \\
\end{tabular}} & \multicolumn{6}{|c|}{ Reliable residue content, \% ( $\mathrm{Au}$ and $\mathrm{Ag}$ in $\mathrm{g} / \mathrm{t}$ ) } \\
\hline $\mathbf{t},{ }^{\mathrm{u}} \mathbf{C}$ & Time, \% & $\mathbf{L}: \mathbf{S}$ & \multicolumn{2}{|c|}{$\mathrm{H}_{2} \mathrm{SO}_{4}$} & pH & \multicolumn{2}{|c|}{$\mathrm{d}, \mathrm{g} / \mathrm{sm}^{3}$} & $\mathbf{C u}$ & $\mathbf{F e}_{\text {total }}$ & As & Sb & $\mathbf{P b}$ & $\mathbf{Z n}$ \\
\hline 35 & 0,5 & 1 & \multicolumn{2}{|c|}{52.7} & 1,96 & \multicolumn{2}{|c|}{1,310} & 14,1 & 30,16 & 0.67 & 0,30 & 7,45 & 1.52 \\
\hline 35 & 0,5 & 2 & \multicolumn{2}{|c|}{52,1} & 2,35 & \multicolumn{2}{|c|}{1,188} & 14.4 & 30,38 & 0,73 & 0,30 & 7,65 & 1,52 \\
\hline 35 & 2 & 1 & \multicolumn{2}{|c|}{62,4} & 2,41 & \multicolumn{2}{|c|}{1,282} & 15,1 & 23,63 & 0,44 & 0,15 & 6,21 & 1,28 \\
\hline 35 & 2 & 2 & \multicolumn{2}{|c|}{52,1} & 2,45 & \multicolumn{2}{|c|}{1,183} & 14,4 & 30,33 & 0,73 & 0,25 & 7,45 & 1,52 \\
\hline 98 & 0,5 & 1 & \multicolumn{2}{|c|}{54,6} & 1,95 & \multicolumn{2}{|c|}{1,325} & 15,0 & 29,92 & 0,85 & 0,30 & 7,65 & 1,52 \\
\hline 98 & 0,5 & 2 & \multicolumn{2}{|c|}{53,5} & 1,88 & \multicolumn{2}{|c|}{1,196} & 15.3 & 30.33 & 0,88 & 0,28 & 7,45 & 1,52 \\
\hline 98 & 2 & 1 & \multicolumn{2}{|c|}{57,7} & 1,44 & \multicolumn{2}{|c|}{1,318} & 14,7 & 29,35 & 0,88 & 0,27 & 7,45 & 1,52 \\
\hline 98 & 2 & 2 & 53 & & 1,52 & & & 14,8 & 29,28 & 0,56 & 0,25 & 7,45 & 1,52 \\
\hline & & & & Extr & action i & n solt & n, \% & & & & & & \\
\hline $\mathbf{B i}$ & Ag & Au & $\mathbf{C u}$ & $\mathbf{F e}_{\mathrm{t}}$ & & As & Sb & $\mathbf{P b}$ & $\mathbf{Z n}$ & & Ubse & at1ons & \\
\hline 0,18 & 174 & 28,4 & 57,6 & 12 & & 48,3 & 4,6 & 1,7 & 36,5 & $\operatorname{Re}$ & $\begin{array}{r}\text { due - br } \\
\text { cry }\end{array}$ & $\begin{array}{l}\text { sht blue } \\
\text { tals }\end{array}$ & large \\
\hline 0,34 & 1,50 & 88,6 & 58,8 & 9 , & & & 90,9 & 40,2 & 56,9 & Residu & - gray & $\begin{array}{l}\text { endrite } \\
\text { ads }\end{array}$ & grains, \\
\hline 0,18 & 162 & 24,0 & 46,2 & 18 & & 59,6 & 43,6 & зд & 36,6 & $\begin{array}{r}\text { Resi } \\
\text { sever }\end{array}$ & $\begin{array}{l}\text { due of } g \\
\text { l crysta }\end{array}$ & $\begin{array}{l}\text { ay-blue } \\
\text { of low } \\
\text { or }\end{array}$ & $\begin{array}{l}\text { olor, } \\
\text { neaded }\end{array}$ \\
\hline 0,20 & 173 & 28,8 & 57,2 & 12 & & 44,0 & 21,6 & 3,0 & 37,2 & $\begin{array}{r}\mathrm{Re} \\
\text { backg }\end{array}$ & $\begin{array}{l}\text { sidue bl } \\
\text { ound, la } \\
\text { spa }\end{array}$ & $\begin{array}{l}\text { and bi } \\
\text { ge blue } \\
\text { kles }\end{array}$ & $\begin{array}{l}\text { Whn } \\
\text { rystals, }\end{array}$ \\
\hline 0,22 & 180 & 27,4 & 53,2 & 9 , & & 31,8 & 1,5 & 0 & 34,1 & Resi & $\begin{array}{r}\text { due larg } \\
\text { spa }\end{array}$ & $\begin{array}{l}\text { blue cr } \\
\text { kles }\end{array}$ & stals, \\
\hline 0,22 & 177 & 28,0 & 53,2 & 10 & & 30,9 & 9,8 & 0,3 & 35,4 & Gray & $\begin{array}{r}\text { loose se } \\
\text { with }\end{array}$ & iment c & vered \\
\hline 0,18 & 166 & 26,0 & 51,5 & 6 , & & 25,4 & 6,1 & 0 & 30,5 & Resi & $\begin{array}{r}\text { lue larg } \\
\text { spe }\end{array}$ & $\begin{array}{l}\text { blue cr } \\
\text { kles }\end{array}$ & stals, \\
\hline 0,20 & 168 & 28,0 & 54,8 & 13 & & 56,0 & 19,5 & 0,3 & 35,4 & & esidue - & luecrys & \\
\hline & Compone & & & solu & ition, g/ & & & xtractio & , \% & & ke, \% & thewe & \\
\hline & $\mathrm{Pb}$ & & & 0 , & 3 & & & 1,6 & & & & & \\
\hline & $\mathrm{Zn}$ & & & 2 & 7 & & & 77,5 & & & & & \\
\hline & As & & & 1 , & 5 & & & 72,2 & & & & & \\
\hline & $\mathrm{Sb}$ & & & 0 , & & & & 41,1 & & & & & \\
\hline & Mo & & & 1, & & & & 33,1 & & & & & \\
\hline & $\mathrm{Bi}$ & & & 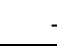 & & & & 0 & & & & & \\
\hline & $\mathrm{Al}_{2} \mathrm{O}_{3}$ & & & 3, & & & & 49,6 & & & & & \\
\hline & $\mathrm{CaO}$ & & & 6, & & & & 79,1 & & & & & \\
\hline & $\mathrm{S}$ & & & 24 &, 0 & & & 81,5 & & & & & \\
\hline
\end{tabular}

Table 5:Results of large-scale laboratory tests of the process of sulphuric acid leaching of dust from copper-made FSF electrofilters with air stirring, $\mathrm{L}: \mathrm{S}=1: 3$, sulfuric acid concentration

\begin{tabular}{|c|c|c|c|c|c|c|c|c|c|c|}
\hline \multirow{3}{*}{$\mathbf{T},{ }^{\circ} \mathbf{C}$} & \multirow{3}{*}{ Time,h } & \multirow{3}{*}{$\begin{array}{l}\text { Oxygen flow } \\
\text { rate, } 1 / \mathrm{min}\end{array}$} & \multicolumn{3}{|c|}{ Characteristiccake } & \multicolumn{5}{|c|}{ Characteristicsolutions } \\
\hline & & & \multirow{2}{*}{$\begin{array}{c}\text { Output, } \% \text { of } \\
\text { originalraise dust }\end{array}$} & \multicolumn{2}{|c|}{ Contents, \% } & \multicolumn{2}{|c|}{ Extraction, \% } & \multicolumn{3}{|c|}{ Contents, g/l } \\
\hline & & & & $\mathrm{Cu}$ & $\mathbf{F e}_{\text {total }}$ & $\mathrm{Cu}$ & $\mathrm{Fe}_{\text {total }}$ & $\mathrm{Cu}^{2+}$ & $\mathrm{Fe}^{2+}$ & $\mathrm{Fe}^{2+}$ \\
\hline 35 & 2 & - & 41,8 & 2,03 & 22,2 & 95,5 & 49,9 & 43,7 & 11,3 & 10,9 \\
\hline 70 & 1 & - & 34,9 & 11,5 & 27,4 & 78,8 & 49,0 & 44,1 & 15,2 & 10,8 \\
\hline 90 & 1 & - & 28,9 & 9,6 & 35,0 & 85,3 & 45,1 & 47,7 & 12,5 & 12,0 \\
\hline 80 & 1 & 0,65 & 25,2 & 0 & 12,6 & 99,9 & 82,8 & 57,0 & 23,9 & 19,3 \\
\hline
\end{tabular}

So, in radiographs, the intensity of peaks with $\mathrm{d} / \mathrm{n}=4.29$; 3,$803 ; 3,00 ; 2,069-, 10$ '10 $\mathrm{m}$ increases dramatically, which indicates the appearance of a significant amount of lead sulfate in cakes. Diffraction peaks with $\mathrm{d} / \mathrm{n}=3.23$; refers to non-deposited iron sulphides, a $2.71 ; 1,69 ; 1$, $6 \mathrm{MO} " 10 \mathrm{~m}$ - to $\mathrm{Fe}_{2} \mathrm{O}_{3}$ and $\mathrm{Fe}_{3} \mathrm{O}_{4}$. It should be noted that differences in the phase compositions of the aqueous and sulfuric acid leaching cakes do not affect pulp settling and filtration. These processes appear to be determined more by particle dispersion than by their phase composition. However, different phase compositions of cakes may affect the way they are processed further. 
The sulfuric acid leaching solutions of FSF dust are characterized, as mentioned above, by a high iron content of up to $24 \mathrm{~g} / \mathrm{l} \mathrm{Fe}$ and up to $20 \mathrm{~g} / \mathrm{l} \mathrm{Fe}$. This makes it necessary to pre-purify the solutions from iron.

Thus, according to the results of sulfuric acid leaching of FSF dust, high copper recovery is possible. Still, a significant transition to an iron solution does not yet allow recommending this method as preferred [6].

Leaching of pre-oxidized dust. A characteristic feature of all the investigated dust leaching methods is the difficulty of simultaneously ensuring high recovery of copper into the solution and minimal transition to the liquid phase of iron Table 6 .

Table 6:Influence of oxidation conditions of dust in the FSF furnace on the form of location in them copper and iron

\begin{tabular}{|c|c|c|c|c|}
\hline \multirow{2}{*}{$\begin{array}{c}\text { Flow rate } 02 \text { per } 1 \mathrm{t} \text { of } \\
\text { dust, } \mathrm{nm}^{3}\end{array}$} & \multirow{2}{*}{ Metal } & \multicolumn{3}{|c|}{ Type of finding of metals, \% } \\
\hline & & Sulphidic & Oxidic & Sulphatic \\
\hline \multirow[t]{3}{*}{0} & $\mathrm{Cu}$ & $10-15$ & $5-10$ & $75-80$ \\
\hline & $\mathrm{Fe}$ & $10-15$ & $\mathrm{Fe}_{3} \mathrm{O}_{4} 3-35$ & $25-30$ \\
\hline & & & $\mathrm{Fe}_{2} \mathrm{O}_{3} 5-15$ & \\
\hline \multirow[t]{4}{*}{50} & $\mathrm{Cu}$ & $5-10$ & $10-15$ & $75-80$ \\
\hline & $\mathrm{Fe}$ & $6-8$ & $\mathrm{Fe}_{3} \mathrm{O}_{4} 70-75$ & $5-10$ \\
\hline & & & $\mathrm{Fe}_{2} \mathrm{O}_{3} 10-30$ & \\
\hline & & & FeO $1-5$ & \\
\hline \multirow[t]{4}{*}{100} & $\mathrm{Cu}$ & $<1$ & $5-10$ & $90-95$ \\
\hline & $\mathrm{Fe}$ & $1-3$ & $\mathrm{Fe}_{3} \mathrm{O}_{4} 70-75$ & $5-10$ \\
\hline & & & $\mathrm{Fe}_{2} \mathrm{O}_{3} 10-30$ & \\
\hline & & & FeO $1-5$ & \\
\hline \multirow[t]{4}{*}{200} & $\mathrm{Cu}$ & $<1$ & $2-5$ & $92-97$ \\
\hline & $\mathrm{Fe}$ & $\sim 1$ & $\mathrm{Fe}_{3} \mathrm{O}_{4} 70-80$ & $5-7$ \\
\hline & & & $\mathrm{Fe}_{2} \mathrm{O}_{3} 10-15$ & \\
\hline & & & $\mathrm{FeO} \sim 1$ & \\
\hline \multirow[t]{4}{*}{300} & $\mathrm{Cu}$ & $<1$ & $2-5$ & $92-97$ \\
\hline & $\mathrm{Fe}$ & $\sim 1$ & $\mathrm{Fe}_{3} \mathrm{O}_{4} 75-80$ & $5-10$ \\
\hline & & & $\mathrm{Fe}_{2} \mathrm{O}_{3} 12-15$ & \\
\hline & & & $\mathrm{FeO} \sim 1$ & \\
\hline
\end{tabular}

Thus, if it is possible to obtain solutions containing a small amount of iron in a neutral (aqueous), wateroxidizing leaching process, the recovery of copper into the solution does not exceed $60-65 \%$. With acidic leaching, the degree of copper recovery increases to 98$99 \%$, but the transition of iron to solution significantly increases. Such solutions are generally subject to degelation by either hydrolysis or a jarosite or hematite process. In this case, pre-treatment of the dust is very promising, as a result of which the solubility in the acids of the copper and iron-containing components becomes different, which ensures the selectivity of copper recovery during the leaching of the dust.
Dust treatment is as follows. In the dust - a gas stream leaving the working space of the melting furnace and having a temperature above $1000{ }^{\circ} \mathrm{C}$, oxygen is supplied, which allows transferring copper sulfides mainly to the oxide form, and iron - to magnetite, as the most stable compound under these conditions. When the dust of the gas stream is cooled in the dust collection system to 700$800{ }^{\circ} \mathrm{C}$ in the presence of unreacted oxygen and sulfur dioxide, copper oxides are sulfated almost wholly, and iron oxides (magnetite) due to their inertia are very insignificant (Table 7).

Table 7:Results of water leaching of FSF electrofilter dust at $80{ }^{\circ} \mathrm{C}, \mathrm{T}:=\mathrm{T}: 4$ and duration of $3 \mathrm{~h}$

\begin{tabular}{|c|c|c|c|c|c|}
\hline \multirow{2}{*}{ Dust } & \multicolumn{2}{|c|}{ Extraction in solution, \% } & \multicolumn{3}{|c|}{ Characteristicofsolutions } \\
\hline & $\mathbf{C u}$ & $\mathbf{F e}_{\text {total }}$ & pH & $\mathrm{Cu}, \mathrm{g} / \mathrm{l}$ & Fe, g/l \\
\hline $\begin{array}{l}\text { FSF produced in the existing model without oxygen } \\
\text { supply in dust - gas flow }\end{array}$ & $70-75$ & $20-25$ & $1,8-2,0$ & $27-30$ & $10-12$ \\
\hline \multirow{4}{*}{$\begin{array}{l}\text { Oxidized at oxygen supply with the flow rate per } 1 \mathrm{t} \\
\text { of dust, nm } 3: 50\end{array}$} & $73-80$ & $15-2$ & $1.9-2.1$ & $29-32$ & $7-10$ \\
\hline & $93-96$ & $5-6$ & $1.8-1.9$ & $37-39$ & $2-2.5$ \\
\hline & $95-98$ & $4-6$ & $1,9-2,0$ & $38-40$ & $1,5-2,5$ \\
\hline & $96-98$ & $7-10$ & $1,9-2,1$ & $38-41$ & $2-4$ \\
\hline
\end{tabular}

The phase composition of the main components of the dust after its pre-oxidation is shown in Table 6. As we see, in dust obtained without oxygen supply, up to $15 \%$ of copper and iron are in the form of sulfides and up to 80 and $30 \%$ - in the form of sulfates. In the dust obtained by supplying 100-200 $\mathrm{nm}^{3}$ of oxygen per 1 ton of dust to the furnace, $92-97 \%$ of copper is in the form of sulfates, and less than $1 \%$ is in the form of sulfides, and $70-80 \%$ iron is in the form of magnetite, and only $5-10 \%$ is in the form of sulfate. Such a flow rate is optically low, since, with a 
decrease in oxygen consumption $\left(50 \mathrm{~nm}^{3} / 1 \mathrm{t}\right.$ of dust $)$, the degree of copper sulfidation decreases and, accordingly, the degree of iron sulfurization increases. A further increase in oxygen consumption $\left(300 \mathrm{~nm}^{3} / 1 \mathrm{t}\right.$ of dust) practically does not affect the phase compositions of copper and iron. The results of the aqueous leaching showed (Table 6) that the recovery of copper into the solution from oxygen oxidized dust at an optimum flow rate of $100-200 \mathrm{~nm}^{3} / \mathrm{t}$ of dust is increased compared to the leaching of dust obtained without oxygen supply from 75 to $98 \%$. The transition of iron to the solution is reduced from 25 to $4 \%$. The solution contains $(\mathrm{g} / \mathrm{l}) 38-40 \mathrm{Cu}, 1.5-$ 2.5 Fe, 1-2 As, 0.3-0.6 Sb and up to 100 sulphate ion. The solution of such a composition, after adjusting its content freely to sulfuric acid, can be used to release copper electrically.

Of all the options considered, the best values for the degree of copper recovery into the solution are water leaching of pre-oxidized dust. Nevertheless, other leaching methods - aqueous, water-oxidative, sulfuric acid - are also acceptable under certain conditions: sulfuric acid with effective purification of solutions from iron, aqueous - with two-stage leaching, water-oxidative - with cheap and non-polluting oxidant solution.

\section{CONCLUSION}

1. A comprehensive study of the technology of copper block production at the Almalyk Mining and Metallurgical Company (AMMC) and the possibility of reducing costs and increasing its competitiveness on this basis in the world market has been established.

2. It has been found that instead of copper pellets used to neutralize free sulfuric acid, copper dust from smelting furnaces can be used.

3. Chemical, mineralogical, phase, and granulometric compositions of the dust of electrofilters CPAMMC were studied. On this basis, the possibility of processing these technogenic formations by the hydrometallurgical method was chosen.

4. Technological parameters of water and acid leaching of dust were investigated, and the most optimal parameters were determined.

5. The introduction of this technology will significantly reduce the cost of production and increase its competitiveness in the world market.

6. Processing of dust in a separate cycle will reduce the ballast turnover of dust in the cycle "FSF furnace - boiler - precipitator recycler - FSF furnace" and increase the productivity of the latter in charge by $10-15 \%$ while increasing the autogenic of the process.

\section{REFERENCES}

1. MirziyoyevSh.M. Ensuring the rule of law and human interests are guaranteed for the development of the country and the well-being of the people. T. Uzbekistan. NMIU, 2017. p.48.

2. Mohd Fakri Muda, Saffuan Wan Ahmad, Fadhluhartini Muftah, Mohd Syahrul Hisyam Mohd Sani Mechanical Behaviour of Mortar Made with Washed Bottom Ashas Sand Replacement, International Journal of Emerging Trends in
Engineering Research, Volume 7, No. 9 September 2019, pp 268-275, https://doi.org/10.30534/ijeter/2019/09792019

3. S.T. Matkarimov, A.A. Yusupkhodjaev, Sh.T. Khojiev, B.T. Berdiyarov, Z. T. M. (2020). Technology for the complex recycling slags of copper production. Journal of Critical Reviews, 7(05). https://doi.org/10.31838/jcr.07.05.38

4. Corby G. Anderson. Robert C. Dunne. Mineral processing and interactive Metallurgy. 100 years of innovation. Feb. 18. 2014.

5. Mechel V.V., Bystrov V.P., Tarasov A.V. Autogenic processes in non-ferrous metallurgy. - M.: Metallurgy. 2016. P.- 410.

6. Fulton Herman Charles. Principles of Metallurgy An Introduction to the Metallurgy of the Metals.2012.

7. San Yee Khaing, Yuichi Sugai, Kyuro Sasaki and Myo Min Tun. Consideration of Influential Factors on Bioleaching of Gold Ore Using Iodide-Oxidizing $\begin{array}{llll}\text { Bacteria.Minerals } 2019, & 9,\end{array}$ doi:10.3390/min 9050274

8. Umarova, I K, Matkarimov S.T, M. D. . (2020). Development of a flotation technology for goldbearing ores of the Amantaytau deposit. OBOGASHCHENIE RUD, 2, 29-33. https://doi.org/10.17580/or.2020.02.05

9. Matkarimov, S. T., Yusupkhodjayev, A. A., Berdiyarov, B. T., Qodirjon Ugli Nosirkhujayev, S., \& Matkarimov, Z. T. (2020). Technology of Deep Processing of Copper Slags by Method of Active Thermal Gravity. International Journal of Advanced Science and Technology, 29(03), 5633-5639.

10. Masadko K. Mikio O. Hiderani N. Processing of dust at the plant of the company "M Kindzoku." Nihon KoreKaim. 2011. № 1166. P. 247 - 251.

11. Areshina N.S., Malts I.E. Kroshkov A.G. Processing of fine dust of reflective melting of copper concentrate of OJSC Kola MMC. Color metallurgists. 2007. № 2. P. 8 - 15.

12. A.Morales. M. Crulles. A. Roc Treatment of copper lash smelter flue dust a for copper and zinc introduction and corsair stabilization. Hydrometallurgy. 105. 2010. P. 148 - 154.

13. Saidova, S., Karimova, T. P., Aribjonova, D. E., Matkarimov, S. T., Beknazarova, G. B., \& Bakhodirova, N. K. (2020). Use Of Clinker Reducing Potential For Reduction Of Copper Losses With Waste Slags On The Converter Process. 7(12), 593-596.

14. Matkarimov, S. T., Nosirkhudjayev, S. Q. U., Ochildiyev, Q. T., Nuraliyev, O. U. U., \& Karimdjonov, B. R. (2019). Technological processes of receiving metals in the conditions of moderate temperatures. International Journal of Innovative Technology and Exploring Engineering, 8(12), 18261828. https://doi.org/10.35940/ijitee.L2856.1081219 